\title{
Correlation and Path Analysis in Shallot (Allium cepa var. ascalonicum Baker.) Genotypes
}

\author{
Fasika Sendek ${ }^{1}$, Hailu Tefera ${ }^{2}$ and Kebede W/Tsadik ${ }^{3 *}$ \\ ${ }^{1}$ Sirinka Agricultural Research center, P O Box 74, Weldia, Welo, Ethiopia \\ ${ }^{2}$ Debre Zeit Agricultural Research Center, P O Box 32, D/Zeit, Ethiopia \\ ${ }^{3}$ Haramaya University, P O Box 138, Dire Dawa, Ethiopia
}

\begin{abstract}
Field experiments were conducted on forty nine shallot genotypes to study the nature of correlations between bulb yield and other related characters at Sirinka and Girana in northeastern Ethiopia. Observations were made on ten plant samples for data analysis. At Girana, total bulb yield per plant showed high and positive phenotypic and genotypic correlations with plant height, leaf number, leaf diameter, bulb splits, marketable yield, biological yield and bulb dry weight. At Sirinka, the same trend was observed at genotypic level while, at phenotypic level, bulb yield correlated positively and significantly with plant height, lateral branches, bulb splits, bulb diameter marketable yield, biological yield and bulb dry weight. At both locations, biological yield, harvest index, marketable yield, bulb splits, pungency, laterals branches, bulb dry weight and bulb diameter exerted a positive direct effect on bulb yield at phenotypic level. At genotypic level, biological yield, bulb splits, harvest index, plant height, leaf diameter, marketable yield and pungency showed a positive direct effect on bulb yield per plant at Grana. The same trend at genotypic level was observed at Sirinka. The correlation of leaf number, plant height and leaf diameter with bulb yield and their positive indirect effects on bulb yield via their contribution to biological yield indicated that they could be considered as useful traits for selection in a breeding program of shallot for bulb yield.
\end{abstract}

Keywords: Shallot; Phenotypic Correlation; Genotypic Correlation; Direct Effect; Indirect Effect; Bulb Yield

\section{Introduction}

Shallot (Allium cepa var. ascalonicum Baker) is ranks among the very important vegetable crops used as a vegetable and condiment in most Ethiopian cuisine. It is widely cultivated as a cash crop mainly by subsistence farmers in the mid and high altitude areas of the country. Local shallot germplasm collections are reported to vary in shape, color, pungency, storability and several other characters (Getachew and Asfaw, 2000). Farmers grow different shallot lines and name them after major production belts. However, as shallot is propagated mainly by asexual method, it is unclear whether these variabilities reflect environmental or genetic background for possible use in breeding programs.

Association of characters among yield, its components, and other economic traits are important for making selection and for combining several desirable attributes in a breeding program. To facilitate selection in a breeding program for high yield, it is logical to examine various components and to give more attention to those having the greatest influence on yield. In correlation studies, it is customary to emphasize large number of plant characters examined in a large number of genotypes and use the correlation to establish an index in deciding the direction of selection (Dudley and Moll, 1969).

Genotypic correlation coefficient provides a measure of genetic association between traits in order to identify the important character to be considered in a breeding program (Pandey and Gritton, 1975). Different researchers have reported associations between different traits in Allium cepa. Dowker et al. (1976), for example, reported a positive correlation between bulb yield and leaf length. Patil and Kale (1985) reported positive association between neck thickness and bulb diameter in onion. As is true for any crop, selection based on any single plant attribute is unlikely to lead to dramatic improvements in the yield potential of Allium spp. Thus, it is suggested that alternative selection criteria are used, based on physiological or morphological characters which contribute to improvement of yield potential (Moot and McNeil, 1995).

Furthermore, path coefficient analysis technique, which involves partitioning of the correlation coefficient into direct and indirect effects via alternative characters or pathways is used to determine which characters affect bulb yield directly or indirectly (Dewey and Lu, 1959; Kalloo et al., 1982; Pal and Singh, 1988). Bulb yield, being a complex outcome of various characters, is considered as the resultant characteristic in onion while the rest of the characters are the causal ones (Kalloo et al., 1982). Therefore, this research intended to study the nature and magnitude of correlation of different traits with bulb yield and how they affect the bulb yield in shallot.

\section{Materials and Methods}

The study was conducted at Sirinka and Girana trial sites of Sirinka Agricultural Research Center, northeastern Ethiopia, during the main growing season (July to November) in 2003. Sirinka Station is located at latitude $11^{\circ} 83^{\prime} \mathrm{N}$ and longitude $39^{\circ} 68^{\prime} \mathrm{E}$ with an altitude of 1850 $\mathrm{m}$.a.s.l. The mean annual rainfall is $950 \mathrm{~mm}$ with a mean maximum and minimum temperature of $26^{\circ} \mathrm{C}$ and $13^{\circ} \mathrm{C}$, respectively (SARC, 2000). The soil type is eutric Vertisol (Samuel, 2001). Girana research site is located about 50 kilometers south of Sirinka Agricultural Research Centre. It is situated at an altitude of $1450 \mathrm{~m}$.a.s.l. and the soil type is clay with $\mathrm{pH}$ of 7.6 (SARC, 2000).

Forty nine shallot genotypes obtained from collections of the National Shallot Improvement Program, including one local and one standard check, were evaluated in a simple lattice design with two replications. The experimental plot size was $2 \mathrm{~m}$ long and $2 \mathrm{~m}$ wide, consisting of 50 plants in rows. Bulbs were planted at a spacing of $40 \mathrm{~cm} \times 20 \mathrm{~cm}$ between rows and plants, respectively. A distance of $1 \mathrm{~m}$ was maintained between plots. The plants in the middle three rows of each plot were used for data collection. The data were subjected to analysis of variance using MSTATC computer program. Path analysis was carried out using Statistical Package for Agricultural Research (SPAR).

\subsection{Correlation Analysis}

Phenotypic correlation of characters refers to both genotypic and environmental effects, while genotypic correlation refers to the inherent association between two 
characters. Both correlations were estimated based on the procedures of Miller et al. (1958) as follows:

Phenotypic correlation $(\mathrm{rp})=\frac{P \operatorname{cov} X . Y}{\sqrt{\left(\sigma 2 \mathrm{p} x^{*} \sigma 2 p y\right)}}$

Genotypic correlation $(\mathrm{rg})=\frac{G \operatorname{cov} X . Y}{\sqrt{(\sigma 2 g x * \sigma 2 g y)}}$

Where: $\mathbf{r p}=$ phenotypic correlation coefficient.

Pcov X.Y $=$ Phenotypic covariance between characters $\mathrm{X}$ and $\mathrm{Y}$

$\sigma 2 p x=$ Phenotypic variance for character $\mathrm{x}$

$\sigma 2 p y=$ Phenotypic variance for character $y$

rg = genotypic correlation coefficient

Gcov $\mathrm{X} . \mathrm{Y}=$ genotypic covariance between characters $\mathrm{X}$ and $\mathrm{Y}$

$\sigma^{2}{ }_{\mathrm{gx}}=$ genotypic variance for character $\mathrm{x}$

$\sigma 2 \mathrm{gy}=$ genotypic variance for character $\mathrm{y}$

\subsection{Path Coefficient Analyses}

The path coefficient analyses were estimated with the simultaneous solution of the following general formula suggested by Dewey and Lu (1959).

$$
\mathrm{rij}=\mathrm{P}_{\mathrm{ij}}+\sum r i k P k j \text {, }
$$

Where, rij = mutual association between the independent character (i) and dependent character (j) as measured by the genotypic correlation coefficient

Pij $=$ components of direct effect on the independent character (i) on the dependent character (j) as measured by the genotypic path coefficient

$\sum$ rikPkj $=$ Summation of components of indirect effects of a given independent character (i) on the given dependent character (j) via all other independent characters (k). To determine Pij values, square matrices of the correlation coefficients between independent characters in all possible pairs inverted and then multiplied by the correlation coefficients between the independent and dependent characters. The residual effects were estimated using the formula:

$$
\sqrt{1}-\mathrm{R}^{2} \quad \text { where, } \mathrm{R}^{2}=\sum \text { Pijrij }
$$

\section{Result and Discussion \\ 3.1. Correlation Analysis}

\subsubsection{Correlation of Bulb Yield per Plant with Its} Components

The estimates of phenotypic and genotypic correlation coefficients both at Girana and at Sirinka (Tables 1 and 2) revealed that the genotypic correlations were of higher magnitude than the corresponding phenotypic ones for the majority of the characters studied, thereby establishing a strong inherent relationship among the attributes studied.

At Girana the interrelationship of total bulb yield per plant was significantly positive with plant height, leaf number, leaf diameter, bulb splits, marketable yield, biological yield and bulb dry weight both at phenotypic and genotypic levels (Table 1). Total bulb yield per plant also had positive and significant genotypic correlation with lateral, bulb splits, bulb diameter and days to maturity.

Total bulb yield at Sirinka correlated positively and significantly with plant height, lateral branches, bulb splits, bulb diameter, marketable yield and biological yield at phenotypic level. Similarly, at genotypic level, total bulb yield correlated positively and significantly with plant height, number of leaves, leaf diameter, bulb diameter, biological yield, marketable yield, and bulb dry weight (Table 2).
The correlation of bulb yield with the vegetative growth suggests that improvement of these characters would improve the photosynthetic capacity of the crop to mobilize and translocate photosynthate to the organ of economic value. This result is in agreement to the work of (Patil and Kale, 1985), Abayneh (2001) and Mohanty (2001) in onion. The positive correlation of bulb yield with bulb splits suggests that genotypes producing a large number of lateral branches could produce a large number of bulb splits per plant, thereby increasing bulb yield per plant although size of individual bulb splits could decrease. On the other hand, the result indicated that shallot genotypes producing a relatively large bulb size could increase bulb yield per plant. Therefore, since most shallot genotypes produce small sized bulbs, improving bulb size would increase bulb yield of marketable size.

Bulb yield per plant exhibited low and positive genotypic correlations with harvest index and total soluble solids, indicating that improving these traits could increase bulb yield per plant to a certain extent. The negative and low magnitudes of genotypic and phenotypic correlations recorded between pungency and bulb yield per plant indicated that increase of bulb yield per plant had no significant impact on pungency of shallot genotypes.

\subsubsection{Correlation among Other Characters}

Marketable yield per plant had positive and high phenotypic and genotypic correlation with plant height, number of leaf per plant, leaf diameter, bulb diameter and bulb dry weight, which indicated that increasing these traits would increase bulb size and marketable yield of shallot (Tables 1 and 2). Plant height showed positive and significant correlation with number of leaves per plant and bulb diameter. This result suggested that increasing plant height could result in an increase of leaf number per plant which, in turn, could lead to higher photosynthetic capacity of the genotypes for better bulb yield with high bulb dry matter_content. The observation is in concordance with the reports of Sadhu and Korla (1976), Patil and Kale (1985), Abayneh (2001) and Mohanty (2001) in onion.

Bulb dry weight correlated positively and highly with the vegetative growth, both at the phenotypic and genotypic levels. This showed that an increase in these characters facilitate increased production of dry matter in shallot, which is an important quality factor in onion bulbs. Harvest index per plant was also positively and significantly associated with leaf diameter and bulb dry weight, indicating that an increase in these characters increases bulb yield per plant. However, its association with plant height, number of leaf per plant and pungency was negative and high, implying that an increase in these traits would increase biomass at the expense of bulb yield and quality. Similarly, the total soluble solids showed negative and high correlation with plant height, number of leaf per plant and bulb diameter. Mc Collum (1968) also reported negative genetic correlation between total soluble solids and bulb diameter in onion.

Days to maturity was correlated positively and highly with leaves per plant, lateral branches and bulb splits per plant. This probably indicates that medium phenological period could result in large biomass accumulation with minimum contribution to bulb yield, due to less efficiency in dry matter partitioning. Plant height showed positive and high correlation with number of leaves per plant, leaf diameter and bulb diameter. This result is in agreement with the reports of Mittal and Srivastava (1965) and Abayneh (2001) in onion. 
Table 1. Correlation coefficients at genotypic (above diagonal) and phenotypic (below diagonal) levels of various characters in shallot genotypes at Girana.

\begin{tabular}{|c|c|c|c|c|c|c|c|c|c|c|c|c|c|c|}
\hline Character & $\mathrm{PH}$ & LPP & LD & LBPP & BSPP & $\mathrm{BD}$ & TYPP & MYPP & BYPP & $\mathrm{HI}$ & BDW & DTM & TSS & PCY \\
\hline $\mathrm{PH}$ & & 0.295 & 0.264 & -0.347 & 0.070 & 0.702 & 0.496 & 0.410 & 0.579 & -0.713 & 0.241 & 0.639 & -0.373 & 0.541 \\
\hline LPP & $0.392^{* *}$ & & -0.489 & 0.441 & 0.833 & 0.025 & 0.313 & 0.087 & 0.415 & -0.672 & 0.140 & 0.609 & -0.450 & 0.090 \\
\hline LD & 0.142 & 0.219 & & -0.613 & 0.116 & -0.206 & 0.985 & 0.885 & 0.762 & 0.733 & 1.096 & 1.885 & 0.237 & 0.112 \\
\hline LBPP & 0.235 & $0.510^{* *}$ & 0.098 & & 0.937 & -0.245 & 0.586 & 0.172 & 0.488 & 0.229 & 0.476 & -0.279 & 0.125 & -0.053 \\
\hline BSPP & $0.433 * *$ & 0.008 & $0.579 * *$ & 0.162 & & 0.006 & 0.306 & 0.044 & 0.261 & -0.160 & 0.133 & -0.123 & -0.016 & -0.241 \\
\hline $\mathrm{BD}$ & 0.034 & -0.105 & 0.105 & -0.002 & $0.319^{*}$ & & 0.887 & 1.009 & 0.892 & 0.114 & 0.868 & 0.416 & -0.316 & 0.106 \\
\hline TYPP & $0.467 * *$ & $0.485^{* *}$ & $0.320^{*}$ & 0.194 & $0.380^{* *}$ & 0.255 & & 0.955 & 0.978 & 0.222 & 1.091 & 0.499 & 0.160 & -0.142 \\
\hline MYPP & $0.915^{* *}$ & $0.473^{* *}$ & $0.322 *$ & 0.203 & 0.229 & $0.295^{*}$ & $0.296^{*}$ & & 0.936 & 0.219 & 0.926 & 0.558 & 0.192 & -0.087 \\
\hline BYPP & $0.891 * *$ & $0.965^{* *}$ & $0.439 * *$ & $0.472 * *$ & $0.338^{*}$ & 0.197 & $0.463^{* *}$ & $0.388^{* *}$ & & 0.025 & 1.039 & 0.564 & 0.077 & -0.069 \\
\hline $\mathrm{HI}$ & 0.074 & 0.267 & $0.287 *$ & 0.276 & 0.026 & -0.030 & 0.056 & -0.188 & $-0.427^{* *}$ & & 0.353 & -0.049 & 0.227 & -0.400 \\
\hline BDW & -0.228 & $0.673^{* *}$ & $0.635^{* *}$ & $0.693 * *$ & $0.374 * *$ & 0.270 & $0.319 *$ & 0.268 & 0.271 & 0.230 & & 0.557 & 0.060 & 0.042 \\
\hline DTM & 0.279 & -0.188 & 0.248 & 0.203 & 0.218 & 0.166 & -0.023 & -0.176 & 0.037 & -0.056 & 0.156 & & 0.077 & 0.231 \\
\hline TSS & 0.074 & 0.190 & 0.056 & 0.181 & 0.218 & 0.232 & 0.046 & 0.136 & 0.132 & 0.142 & -0.019 & -0.084 & & -0.388 \\
\hline PCY & -0.183 & 0.028 & 0.049 & -0.138 & -0.049 & -0.089 & -0.083 & -0.171 & 0.061 & -0.054 & 0.075 & 0.082 & 0.263 & \\
\hline
\end{tabular}

$P H=$ plant height, $L P P=$ leaves per plant, $L D=$ leaf diameter, $L B P P=$ lateral branches per plant, $B S P P=$ bulb splits per plant, $B D=$ bulb diameter, $T Y P P=$ total yield per plant, $M Y P P=$ marketable yield per plant, $B Y P P=$ biological yield per plant, $H I=$ barvest index, $B D W=$ bulb dry weight, DTM $=$ days to maturity, TSS = total soluble solids, and $P C Y=$ pungency.

*, ** indicate significant difference at $5 \%$ and $1 \%$ probability levels respectively.

The phenotypic correlation coefficients must exceed 0.288 and 0.372 to be significant at $5 \%$ and $1 \%$ probability levels, respectively.

Table 2. Correlation coefficients at genotypic (above diagonal) and phenotypic (below diagonal) levels of various characters in shallot genotypes at Sirinka.

\begin{tabular}{|c|c|c|c|c|c|c|c|c|c|c|c|c|c|c|}
\hline Characters & $\mathrm{PH}$ & LPP & LD & LBPP & BSPP & $\mathrm{BD}$ & TYPP & MYPP & BYPP & $\mathrm{HI}$ & BDW & DTM & (TSS) & PCY \\
\hline $\mathrm{PH}$ & & 0.475 & 0.731 & 0.071 & -0.148 & 1.007 & 0.751 & 0.773 & 0.771 & -0.156 & 0.519 & -0.681 & -0.052 & 0.417 \\
\hline LPP & $0.335^{*}$ & & 0.278 & 1.174 & 0.409 & -0.109 & 0.347 & 0.330 & 0.464 & -0.783 & 0.051 & 0.344 & -0.510 & 0.187 \\
\hline LD & $0.295^{*}$ & $0.500^{* *}$ & & -0.218 & -0.600 & 0.335 & 0.452 & 0.533 & 0.510 & -0.238 & 0.292 & 0.056 & -0.260 & 0.138 \\
\hline LBPP & 0.095 & $0.612 * *$ & 0.016 & & 0.942 & -0.431 & 0.239 & 0.091 & 0.347 & -0.765 & 0.295 & 0.559 & -0.661 & 0.246 \\
\hline BSPP & $0.613^{* *}$ & -0.264 & $0.465^{* *}$ & -0.009 & & -0.137 & 0.070 & -0.072 & 0.058 & -0.036 & 0.106 & 0.303 & 0.006 & -0.044 \\
\hline $\mathrm{BD}$ & -0.092 & -0.256 & 0.229 & -0.015 & $0.354^{*}$ & & 0.619 & 0.670 & 0.564 & 0.359 & 0.677 & -0.517 & 0.043 & 0.096 \\
\hline TYPP & $0.402^{* *}$ & 0.263 & 0.158 & $0.420 * *$ & $0.375^{* *}$ & $0.559 * *$ & & 0.993 & 0.988 & 0.139 & 0.936 & 0.069 & 0.178 & 0.104 \\
\hline MYPP & $0.970 * *$ & $0.450^{* *}$ & 0.109 & 0.062 & $0.469 * *$ & $0.319 *$ & $0.579 * *$ & & 0.992 & 0.070 & 0.912 & 0.029 & 0.153 & 0.079 \\
\hline BYPP & $0.958^{* *}$ & $0.982 * *$ & $0.376^{* *}$ & 0.254 & 0.187 & $0.446^{* *}$ & $0.464 * *$ & $0.560 * *$ & & -0.008 & 0.864 & 0.136 & 0.130 & 0.068 \\
\hline $\mathrm{HI}$ & -0.045 & 0.110 & 0.134 & 0.128 & 0.002 & -0.165 & -0.072 & -0.445 & -0.001 & & 0.548 & -0.548 & 0.427 & 0.170 \\
\hline BDW & 0.277 & $0.478^{* *}$ & $0.556^{* *}$ & $0.531^{* *}$ & $0.403^{* *}$ & 0.029 & 0.130 & 0.088 & 0.126 & 0.209 & & 0.400 & 0.180 & -0.035 \\
\hline DTM & 0.071 & 0.130 & 0.124 & 0.140 & 0.143 & -0.126 & 0.098 & 0.158 & 0.128 & 0.227 & -0.023 & & -0.869 & -0.350 \\
\hline TSS & -0.096 & 0.124 & 0.279 & 0.079 & 0.164 & 0.130 & 0.066 & -0.105 & -0.250 & -0.097 & $-.324 *$ & 0.103 & & -0.096 \\
\hline PCY & -0.019 & -0.185 & 0.015 & 0.128 & 0.070 & 0.092 & 0.103 & 0.093 & -0.016 & 0.116 & 0.157 & 0.130 & 0.227 & \\
\hline
\end{tabular}

$P H=$ plant height, $L P P=$ leaves per plant, $L D=$ leaf diameter, $L B P P=$ lateral branches per plant, $B S P P=$ bulb splits per plant, $B D=b u l b$ diameter, $T Y P P=$ total yield per plant, $M Y P P=$ marketable yield per plant, $B Y P P=$ biological yield per plant, $H I=$ harvest index, $B D W=$ bulb dry weight, DTM= days to maturity, TSS= total soluble solids, and $P C Y=$ pungency.

*, ** indicate significant difference at $5 \%$ and $1 \%$ probability levels, respectively.

The phenotypic correlation coefficients must exceed 0.288 and 0.372 to be significant at $5 \%$ and $1 \%$ probability levels respectively. 


\subsection{Path Analysis}

3.2.1. Phenotypic Direct and Indirect Effects of Characters on Bulb Yield

At Girana, biological yield (0.847) and harvest index (0.169) had positive direct effects on bulb yield (Table 3 ). Other characters which showed positive direct effects on bulb yield were marketable yield, bulb splits, pungency, bulb dry weight, number of lateral branches per plant and bulb diameter. Plant height showed negative direct effect on bulb yield per plant, indicating that its negative direct effect was counterbalanced by its positive indirect effect via biological yield, bulb splits per plant and marketable yield per plant. These characters could be considered as main components of selection in a breeding program for obtaining higher bulb yield. This finding is supported by the work of Abayneh (2001) and Singh (1981) who reported that biological yield and harvest index contributed direct effects in onion bulb yield.
At Sirinka, biological yield (0.930) and harvest index (0.152) also directly affected bulb yield per plant (Table 4). Low magnitudes of negative direct effects were observed on bulb yield per plant via leaves per plant, leaf diameter and total soluble solids. In addition to its direct positive effect on bulb yield per plant, harvest index also exhibited positive indirect effects via bulb diameter, bulb dry weight, days to maturity, total soluble solids and pungency. Negative indirect effects of harvest index were observed through traits such as leaf per plant, leaf diameter, marketable yield and biological yield per plant. This result is in agreement with the work of Abayneh (2001) who reported that harvest index had a negative indirect effect on biological yield per plant in onion. Bulb dry weight demonstrated a favorable positive indirect effect through bulb diameter, marketable yield, biological yield and harvest index. In addition, a near absence effect was observed via the other characters.

Table 3. Phenotypic direct (bold face) and indirect effects of various characters on bulb yield per plant of shallot genotypes at Girana.

\begin{tabular}{llllllllllllll}
\hline Character & PH & LPP & LD & LB & BSPP & BD & MY & BYPP & HI & BDW & DTM & TSS & PCY \\
\hline PH & -0.0 .35 & -0.022 & 0.000 & 0.001 & 0.013 & 0.001 & 0.032 & 0.329 & -0.072 & 0.003 & 0.000 & 0.001 & 0.004 \\
LPP & -0.014 & -0.057 & 0.000 & 0.006 & 0.046 & 0.000 & 0.032 & 0.392 & -0.032 & 0.004 & 0.000 & 0.000 & 0.001 \\
LD & -0.008 & -0.008 & 0.002 & 0.003 & 0.001 & 0.000 & 0.025 & 0.167 & 0.009 & 0.004 & 0.000 & -0.001 & 0.001 \\
LBPP & -0.003 & -0.029 & 0.000 & 0.013 & 0.035 & 0.000 & 0.022 & 0.286 & -0.005 & 0.005 & 0.000 & -0.001 & -0.001 \\
BSPP & -0.006 & -0.033 & 0.000 & 0.005 & 0.080 & 0.000 & 0.34 & 0.399 & 0.004 & 0.004 & 0.000 & -0.001 & -0.003 \\
BD & -0.011 & 0.000 & 0.000 & -0.001 & 0.003 & 0.002 & 0.051 & 0.371 & 0.047 & 0.005 & 0.000 & 0.000 & 0.001 \\
TYPP & -0.010 & -0.017 & 0.000 & 0.003 & 0.026 & 0.001 & 0.107 & 0.755 & 0.045 & 0.009 & 0.000 & -0.002 & -0.001 \\
MYPP & -0.014 & -0.026 & 0.000 & 0.004 & 0.038 & 0.001 & 0.096 & 0.847 & 0.013 & 0.010 & 0.000 & -0.002 & -0.001 \\
BYPP & 0.015 & 0.011 & 0.000 & 0.000 & 0.002 & 0.001 & 0.029 & 0.063 & 0.169 & 0.003 & 0.000 & -0.003 & -0.002 \\
HI & -0.008 & -0.015 & 0.000 & 0.004 & 0.022 & 0.001 & 0.068 & 0.0570 & 0.038 & 0.015 & 0.000 & -0.001 & 0.000 \\
BDW & -0.005 & 0.003 & 0.000 & -0.002 & -0.002 & 0.000 & 0.022 & 0.210 & -0.011 & 0.004 & -0.001 & -0.001 & 0.000 \\
DTM & 0.003 & 0.001 & 0.000 & 0.002 & 0.011 & 0.000 & 0.023 & 0.153 & 0.048 & 0.003 & 0.000 & -0.009 & -0.003 \\
TSS & -0.009 & -0.005 & 0.000 & -0.001 & -0.014 & 0.000 & -0.010 & -0.041 & -0.023 & 0.001 & 0.000 & 0.002 & 0.016 \\
\hline
\end{tabular}

$P H=$ plant height, $L P P=$ leaves per plant, $L D=$ leaf diameter, $L B P P=$ lateral branches per plant, $B S P P=$ bulb splits per plant, $B D=$ bulb diameter, TYPP = total yield per plant, $M Y P P=$ marketable yield per plant, BYPP = biological yield per plant, $H I=$ harvest index, $B D W=$ bulb dry weight, DTM= days to maturity, TSS= total soluble solids, and PCY = pungency.

Residual effect $=0.0161$

Table 4. Phenotypic direct (bold face) and indirect effects of various characters on bulb yield per plant of shallot genotypes at Sirinka.

\begin{tabular}{|c|c|c|c|c|c|c|c|c|c|c|c|c|c|}
\hline Character & $\mathrm{PH}$ & LPP & $\mathrm{LD}$ & $\mathrm{LB}$ & BSPP & $\mathrm{BD}$ & MY & BYPP & $\mathrm{HI}$ & BDW & DTM & TSS & PCY \\
\hline $\mathrm{PH}$ & 0.014 & -0.010 & -0.004 & 0.000 & 0.000 & 0.002 & 0.034 & 0.521 & 0.000 & 0.000 & 0.000 & 0.000 & 0.004 \\
\hline LPP & 0.005 & -0.031 & -0.002 & 0.004 & 0.013 & 0.000 & 0.018 & 0.432 & -0.068 & 0.000 & 0.002 & 0.001 & 0.002 \\
\hline LD & 0.007 & -0.009 & -0.008 & 0.001 & -0.007 & 0.002 & 0.027 & 0.415 & -0.011 & 0.000 & 0.001 & 0.000 & 0.002 \\
\hline LBPP & 0.000 & -0.019 & -0.001 & 0.007 & 0.017 & -0.002 & 0.004 & 0.174 & -0.025 & 0.000 & 0.001 & 0.001 & 0.002 \\
\hline BSPP & 0.000 & -0.014 & 0.002 & 0.004 & 0.027 & -0.001 & 0.006 & 0.237 & 0.000 & 0.000 & 0.001 & 0.000 & 0.000 \\
\hline BD & 0.005 & 0.000 & -0.002 & -0.002 & -0.003 & 0.007 & 0.026 & 0.350 & 0.019 & 0.001 & -0.001 & -0.001 & 0.001 \\
\hline TYPP & 0.008 & -0.010 & -0.004 & 0.000 & 0.003 & 0.003 & 0.058 & 0.891 & -0.017 & 0.001 & 0.001 & -0.001 & 0.001 \\
\hline MYPP & 0.008 & -0.014 & -0.004 & 0.001 & 0.007 & 0.003 & 0.056 & 0.930 & -0.007 & 0.001 & 0.001 & 0.000 & 0.001 \\
\hline BYPP & 0.000 & 0.014 & 0.001 & -.0 .001 & 0.000 & 0.001 & 0.006 & -0.042 & 0.152 & 0.001 & 0.001 & -0.001 & 0.002 \\
\hline $\mathrm{HI}$ & 0.003 & 0.004 & -0.001 & -0.001 & 0.001 & 0.003 & 0.032 & 0.445 & 0.042 & 0.002 & 0.001 & 0.000 & 0.000 \\
\hline BDW & 0.000 & -0.007 & -0.001 & 0.001 & 0.003 & -0.001 & 0.008 & 0.115 & 0.020 & 0.000 & 0.008 & 0.000 & -0.003 \\
\hline DTM & 0.001 & 0.010 & 0.001 & -0.002 & -0.003 & 0.000 & 0.009 & 0.074 & 0.042 & 0.000 & -0.001 & -0.003 & 0.000 \\
\hline TSS & 0.003 & -0.004 & -0.001 & 0.001 & 0.000 & 0.001 & 0.005 & 0.065 & 0.019 & 0.000 & -0.001 & 0.000 & 0.016 \\
\hline
\end{tabular}


3.2.2. Genotypic Direct and Indirect Effects of Characters on Bulb Yield

At Girana, genotypic direct effect on bulb yield per plant was exerted by biological yield (0.987), bulb splits per plant (0.237) and harvest index (0.115). Low magnitude and positive direct effects were also exhibited by plant height, leaf diameter, marketable yield per plant, and pungency (Table 5). Number of leaves per plant, however, exhibited a negative direct effect on bulb yield per plant. Bulb dry weight also affected bulb yield per plant unfavorably. Bulb splits per plant showed a positive direct effect on bulb yield per plant through the indirect positive influence on plant height, leaf diameter, lateral branches, marketable yield per plant, biological yield per plant, days to maturity and total soluble solids per plant. The findings showed that the influence of bulb dry weight was counterbalanced by the positive indirect effects of biological yield per plant, harvest index, bulb splits per plant, marketable yield per plant, leaf diameter, plant height and pungency.

At Sirinka, biological yield per plant showed maximum positive direct effect (0.846) followed by harvest index, marketable yield per plant, bulb dry weight, pungency, bulb diameter, bulb splits, days to maturity and total soluble solids (Table 6). Biological yield also showed a favorable indirect influence on bulb yield via leaves per plant, bulbs splits per plant, bulb diameter, marketable yield, bulb dry weight per plant, total soluble solids and pungency. In addition to the positive direct effect on bulb yield per plant, marketable yield exerted a favorable indirect influence on bulb yield via leaves per plant, bulb diameter, biological yield, harvest index, bulb dry weight per plant, total soluble solids and pungency. The overall finding is in conformity with Kalloo et al. (1982) and Abayneh (2001) who reported that biological yield, leaf diameter, harvest index and plant height exerted a positive direct effect on bulb yield of onion. Pal and Singh (1988) reported that selection based on weight and diameter of bulb was useful for onion. Similarly, Mohanty (2001) suggested that leaf number per plant be envisaged independently or in combination with other vegetative characters to circumvent the bulb yield of onion.

Generally, each of the characters considered in this study has influenced bulb yield directly and indirectly. At both locations the residual effects were not significantly high, which demonstrated that the traits considered were enough to explain the direct and indirect effects on bulb yield per plant. The estimates of the direct and indirect effects were more pronounced in genotypic path than the phenotypic path, particularly at Girana site rather than at Sirinka, indicating better genetic expression of the traits and their contribution towards bulb yield as a tool for selection of shallot genotypes under Girana condition.

Table 5. Genotypic direct (bold face) and indirect effects of various characters on bulb yield per plant of shallot genotypes at Girana.

\begin{tabular}{|c|c|c|c|c|c|c|c|c|c|c|c|c|c|}
\hline Character & $\mathrm{PH}$ & LPP & $\mathrm{LD}$ & $\mathrm{LB}$ & BSPP & $\mathrm{BD}$ & MY & BYPP & $\mathrm{HI}$ & BDW & DTM & TSS & PCY \\
\hline PH & 0.034 & -0.058 & 0.015 & 0.003 & 0.017 & -0.032 & 0.029 & 0.571 & -0.082 & -0.013 & -0.017 & -0.015 & 0.014 \\
\hline LPP & 0.010 & -0.196 & -0.027 & -0.004 & 0.197 & -0.001 & 0.006 & 0.409 & -0.077 & -0.008 & -0.016 & -0.017 & 0.002 \\
\hline LD & 0.009 & 0.096 & 0.056 & 0.006 & 0.027 & 0.009 & 0.63 & 0.751 & 0.084 & -0.060 & -0.050 & 0.009 & 0.003 \\
\hline LBPP & -0.012 & -0.087 & -0.034 & -0.009 & 0.222 & 0.011 & 0.012 & 0.481 & 0.026 & -0.026 & 0.007 & -0.005 & -0.001 \\
\hline BSPP & 0.002 & -0.164 & 0.007 & -0.008 & 0.237 & 0.000 & 0.003 & 0.258 & -0.018 & -0.007 & 0.003 & 0.001 & -0.006 \\
\hline BD & 0.024 & -0.005 & -0.012 & 0.002 & 0.001 & -0.045 & 0.072 & 0.880 & 0.013 & -0.047 & -0.011 & 0.012 & 0.003 \\
\hline TYPP & 0.014 & -0.017 & 0.050 & -0.002 & 0.010 & -0.045 & 0.071 & 0.924 & 0.025 & -0.050 & -0.015 & -0.007 & -0.002 \\
\hline MYPP & 0.020 & -0.081 & 0.043 & -0.004 & 0.062 & -0.040 & 0.067 & 0.987 & 0.003 & -0.057 & -0.015 & -0.003 & -0.002 \\
\hline BYPP & -0.024 & 0.132 & 0.041 & -0.002 & -0.038 & -0.005 & 0.016 & 0.025 & 0.115 & -0.019 & 0.001 & -0.009 & -0.011 \\
\hline $\mathrm{HI}$ & 0.008 & -0.028 & 0.062 & -0.004 & 0.031 & -0.039 & 0.066 & 1.025 & 0.041 & -0.054 & -0.015 & -0.002 & 0.001 \\
\hline BDW & 0.022 & -0.119 & 0.106 & 0.003 & -0.029 & -0.019 & 0.040 & 0.556 & -0.006 & -0.030 & -0.027 & -0.003 & 0.006 \\
\hline DTM & -0.013 & 0.088 & 0.013 & -0.001 & -0.004 & 0.014 & 0.014 & 0.076 & 0.026 & -0.003 & -0.002 & -0.039 & -0.010 \\
\hline TSS & 0.018 & -0.018 & 0.006 & 0.000 & 0.057 & -0.005 & -0.006 & -0.068 & -0.046 & -0.002 & -0.006 & 0.015 & 0.027 \\
\hline
\end{tabular}

Table 6. Genotypic direct (bold face) and indirect effects of various characters on bulb yield per plant of shallot genotypes at Sirinka.

\begin{tabular}{llllllllllllll}
\hline Character & PH & LPP & LD & LB & BSPP & BD & MY & BY & HI & BDW & DTM & TSS & PCY \\
\hline PH & -0.012 & 0.012 & -0.019 & -0.001 & -0.002 & 0.031 & 0.074 & 0.652 & -0.016 & 0.025 & -0.006 & 0.000 & 0.013 \\
LPP & -0.006 & 0.025 & -0.007 & -0.015 & 0.006 & -0.003 & 0.032 & 0.392 & -0.079 & -0.002 & -0.003 & -0.004 & 0.006 \\
LD & -0.009 & 0.007 & -0.026 & 0.003 & -0.008 & 0.010 & 0.051 & 0.431 & -0.024 & 0.014 & 0.000 & -0.002 & 0.004 \\
LBPP & -0.001 & 0.029 & 0.006 & -0.012 & 0.013 & -0.013 & 0.009 & 0.294 & 0.077 & -0.014 & -0.005 & -0.005 & 0.008 \\
BSPP & 0.002 & 0.010 & 0.015 & -0.012 & 0.014 & -0.004 & -0.007 & 0.049 & -0.004 & 0.005 & 0.003 & 0.000 & -0.001 \\
BD & -0.013 & -0.003 & -0.009 & 0.005 & -0.002 & 0.031 & 0.064 & 0.477 & 0.036 & 0.032 & -0.005 & 0.000 & 0.003 \\
TYPP & -0.010 & 0.008 & -0.014 & -0.001 & -0.001 & 0.021 & 0.096 & 0.839 & 0.007 & 0.044 & 0.000 & 0.001 & 0.002 \\
MYPP & -0.010 & 0.011 & -0.013 & -0.004 & 0.001 & 0.017 & 0.095 & 0.846 & -0.001 & 0.041 & -0.001 & 0.001 & 0.002 \\
BYPP & 0.002 & -0.019 & 0.006 & 0.010 & 0.000 & 0.011 & 0.007 & -0.007 & 0.101 & 0.026 & -0.005 & 0.003 & 0.005 \\
HI & -0.006 & -0.001 & -0.007 & 0.004 & 0.001 & 0.021 & 0.087 & 0.731 & 0.055 & 0.048 & 0.003 & 0.001 & -0.001 \\
BDW & 0.008 & 0.008 & -0.001 & -0.007 & 0.004 & -0.016 & 0.003 & 0.115 & -0.055 & 0.019 & 0.009 & -0.007 & 0.011 \\
DTM & 0.001 & -0.013 & 0.007 & 0.008 & 0.000 & 0.001 & 0.015 & 0.110 & 0.043 & 0.009 & -0.008 & 0.008 & -0.003 \\
TSS & -0.005 & 0.005 & -0.004 & -0.003 & -0.001 & 0.003 & 0.008 & 0.058 & 0.017 & -0.002 & -0.003 & -0.001 & 0.031 \\
\hline
\end{tabular}

$\mathrm{PH}=$ plant height, $\mathrm{LPP}=$ leaves per plant, $\mathrm{LD}=$ leaf diameter, $\mathrm{LBPP}=$ lateral branches per plant, $\mathrm{BSPP}=$ bulb splits per plant, $\mathrm{BD}=\mathrm{bulb}$ diameter, $\mathrm{TYPP}=$ total yield per plant, $M Y P P=$ marketable yield per plant, $B Y P P=$ biological yield per plant, $H I=$ barvest index, $B D W=$ bulb dry weight, $D T M=$ days to maturity, TSS = total soluble solids, and PCY= pungency.

Residual effect $=0.0007$ 


\section{Conclusion}

Total bulb yield per plant in shallot was found to be associated positively and significantly with plant height, bulb splits, biological yield and marketable yield per plant at phenotypic level at Girana and Sirinka study sites. Similarly, at genotypic level, bulb yield per plant correlated positively and significantly with plant height, number of leaves, leaf diameter, bulb diameter, biological yield and marketable yield in both locations. The findings indicated that most of the characters considered in this study had positive and high intercharacter correlation at phenotypic and genotypic levels, which indicated the possibility of correlated response to selection and that, with an increase in one, there is a possibility of increment in the other.

In path coefficient analysis at phenotypic level, biological yield, harvest index, marketable yield, bulb splits, lateral branches, bulb diameter and pungency showed a positive direct effect on bulb yield per plant. At genotypic level, biological yield, bulb splits, harvest index, marketable yield and pungency showed a positive direct effect on bulb yield. At both locations, the residual values were low, which indicated the traits considered have explained the path analysis pattern.

Both at Girana and Sirinka, genotypic correlations were found to be higher in magnitude than that of phenotypic for the majority of the characters studied. This indicated that genetic factors played a major role in these associations among the characters. Vegetative traits such as plant height, leaf number, leaf diameter and bulb diameter, which showed positive correlation with bulb yield and also positively affected bulb yield via their contribution to biological yield, appear to be useful traits to be considered in the selection of shallot for bulb yield.

\section{References}

Abayneh, M. 2001. Variability and association among bulb yield, quality and related traits in onion (Allium cepa.L). M.Sc. Thesis submitted to College of Agriculture, Alemaya University.

Dewey, D.R and Lu, K.H. 1959. A correlation and path coefficient analysis of components of crested wheat grass seed production. Agronomy Journal 51:515-558.

Dowker, B.D., Hardwick, R.C., Fennell, J.F.M. and Andrews, D.J. 1976. Genotypic and environmental correlations between leaf growth and bulb size in onion. Annals of Applied Biology 82:341-348.

Dudley, J.W. and Moll, R.H. 1969. Interpretation and use of estimates of heritability and genetic variances in plant breeding. Crop Science 9: 257-267.
Getachew, T. and Asfaw, Z. 2000. Research achievements in garlic and shallot. Research Bull. Report No. 36. EARO, Ethiopia.

Kalloo, J.C., Pandey, S.C., Lal, S. and Pandita, M.L. 1982. Correlation and path analysis studies in onion. Haryana Journal of Horticultural Sciences 11:97.

Mc Collum, G.D. 1968. Heritability and genetic correlation of soluble solids, bulb size, and shape in white sweet Spanish onion. Canadian Journal of Genetics and Cytology 10:508-514.

Miller, P.A., Williams, J.C. Robinson, H.F. and Comostock, R.E. 1958. Estimates of genotypic and environment variances in upland cotton and their implications in selection. Agronomy Journal 50:126131.

Mittal, S.P and Srivastava, G. 1965. Bulb yield in relation to bulb size, plant height and leaf length in onion (Allium repa L.). Journal of Botany 58: 187-195.

Mohanty, B.K. 2001. Genetic variability, interrelationship and path analysis in onion. Journal of Tropical Agriculture 39:17-20.

Moot, D.J. and McNeil, D.J. 1995. Yield components, harvest index and plant type in relation to yield differences in field pea. Euphytica 86:31-40.

Pal, N. and Singh, N. 1988. Analysis of genetic architecture of pungency (pyruvic acid) in onion. Euphytica 80:379.

Pandey, S, and Gritton, E.T. 1975. Genotypic and phenotypic correlations in peas. Crop Science 15:353356.

Patil, R.S. and Kale, P.N. 1985. Correlation studies on bulb characters and storage losses in onion. Journal of Maharashtra Agricultural University 10:38-39.

Samuel, M. 2001. Evaluation of the effect of cutting height on dry matter, forage yield and quality of Napier grass in Northeastern part of Wello. Proceedings of the $9^{\text {th }}$ Annual Conference of the Ethiopian Society of Animal Production held on Aug.30-31. Addis Ababa, Ethiopia.pp210.

Sandhu, J.S. and Korla, B.N. 1976. Inter-relationship between economic characters and selection indices in onion seed crop. Indian Journal of Horticultural Science 33:170-172.

SARC (Sirinka Agricultural Research Center). 2000 Progress report 2000. Sirinka, Ethiopia.

Singh, R.P. 1981. Genetic evaluation and path analysis in onion. Madras Agricultural Journal 68:61-80. 